\title{
Characterization of a novel sound absorption material derived from waste agricultural film
}

\author{
Lei Wang, Fu-Shen Zhang* \\ Department of Solid Waste Treatment and Recycling, Research Center for Eco-Environmental Sciences, Chinese Academy of Sciences, Beijing 100085, China
} University of Chinese Academy of Sciences, Beijing 100049, China

\section{H I G H L I G H T S}

- A novel sound absorption material was produced using waste agricultural film.

- The material had a porous structure with cavities, perforations, and an air layer.

- It exhibited excellent sound absorption in both low and high frequency ranges.

- Low-frequency absorption could be adjusted as per the actual noise absorption.

\section{A R T I C L E I N F O}

\section{Article history:}

Received 2 April 2017

Received in revised form 20 July 2017

Accepted 26 July 2017

Available online 22 September 2017

\section{Keywords:}

Waste plastics

Sound absorption

Porous material

Perforated plate

\section{G R A P H I C A L A B S T R A C T}

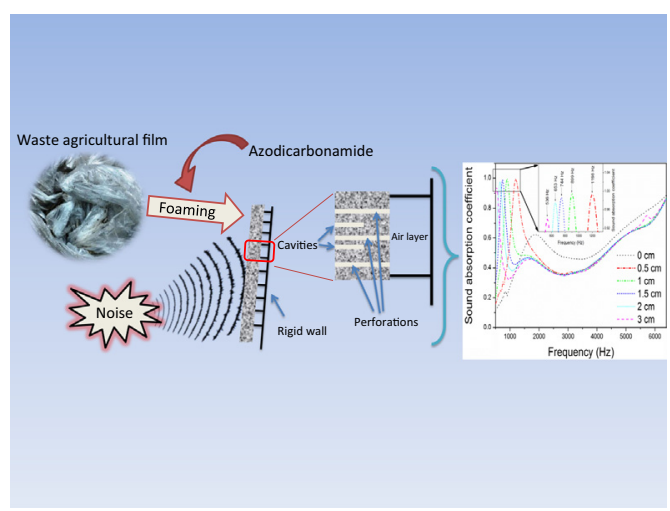

\begin{abstract}
A B S T R A C T
A comprehensive sound absorption material was developed using waste agricultural plastic film as raw material. Comparing to traditional acoustic materials such as porous materials and perforated plates, the new material exhibited excellent sound absorption capability in both low- and high-frequency ranges and had a complex structure with perforations, cavities, and an air layer. The optimal average sound absorption coefficients of the material were 0.44 and 0.53 within the frequency ranges of 200-1600 and $500-6400 \mathrm{~Hz}$, respectively. Furthermore, the low-frequency absorption range of the material could be adjusted according to the actual noise absorption requirements, thus broadening its application ranges. The density of the material is $0.55 \mathrm{~g} / \mathrm{cm}^{3}$ while its thickness is only $1 \mathrm{~cm}$. Thus, it is lighter than most conventional sound absorption materials. The compressive strength of the samples were $0.56 \pm 0.01 \mathrm{MPa}$ (unmanufactured), $0.51 \pm 0.01 \mathrm{MPa}$ (4 perforations) and $0.45 \pm 0.02 \mathrm{MPa}$ (4 perforations and 12 cavities) respectively and, its flexural strength was $91.2 \pm 1.22 \mathrm{~N}$. Interfering tests indicated that water coverage could decline the sound absorption efficiency in all frequency ranges, while sand coverage only declined the low frequency absorption, but increased the high frequency absorption effect of the material. Accordingly, it is believed that the new waste-derived material is quite suitable for application on bridges and inside tunnels during high-speed road construction, and also appropriate for using as parts of vehicles and ceilings etc.
\end{abstract}

(c) 2017 Elsevier Ltd. All rights reserved.

\footnotetext{
* Corresponding author at: Department of Solid Waste Treatment and Recycling, Research Center for Eco-Environmental Sciences, Chinese Academy of Sciences, Beijing 100085, China.

E-mail address: fszhang@rcees.ac.cn (F.-S. Zhang).
} 


\section{Introduction}

Over the past decade, both "white pollution" and noise pollution have become serious global issues. For instance, more than 2 million tons of agricultural film is used globally every year, most of which will be converted into waste in one or two years, and will do great harm to the environment without proper disposition. Studies have shown that waste film can reduce land output and cause significant environmental pollution [1]. Meanwhile, given the changes in society, noise pollution has become a widespread health and social problem in most countries, especially in the urban areas, causing physical and emotional distress to human [2-4] and animals alike [5]. To tackle these serious problems, scientists and engineers are devoting efforts to develop various sound-absorption materials. Significant achievements have been made in the development of porous materials and perforated plates for sound absorption. Porous materials can be made from organic materials (plastics and rubbers) and inorganic materials (metals and minerals), such as open-cell polyolefin-based foams [6], aluminium foam [7], ceramic hollow sphere [8] and hempconcretes with lime-pozzolan binders [9]. They all show superior acoustic properties. Porous materials are generally used for highfrequency noise control. As an acoustic structure, perforated plates show excellent abilities for low- and middle-frequency noise control. Perforated plates $[10,11]$ and mic-perforated plates $[12,13]$ have been used to control noise in extensive ranges for years. Researchers filled porous materials into the back air layer of perforated plates to improve their sound absorption properties in highfrequency range $[14,15]$. However, this method increased the material cost and was difficult to use. Thus far, the high cost of the materials and the increase in their weight are significant disadvantages when it comes to large-scale application. To the best of our knowledge, there have been few studies on such composite acoustic structures. In the current study, a novel comprehensive sound absorption material with excellent sound absorption in both low- and high-frequency ranges was developed.

\section{Materials and methods}

\subsection{Materials and equipment}

Waste agricultural film used in this study was provided by Hui Run Rubber and Plastic Co., China. The foaming agent (azodicarbonamide) was provided by Zhong Sheng Wei Ye Chemical Co., and the sound absorption coefficients were measured using an AWA8551 test system (Figs. 1 and 2). Sand was bought in the market (40-80 mesh)

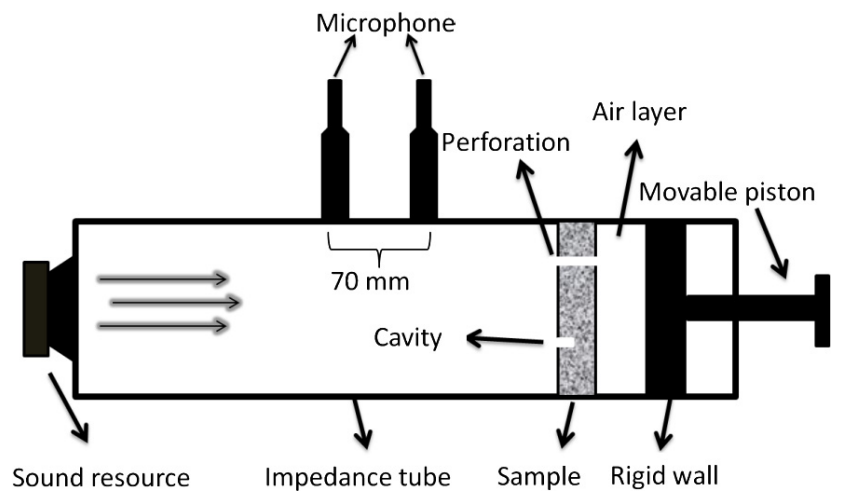

Fig. 1. Schematic diagram of the sound absorption system for low-frequency testing.

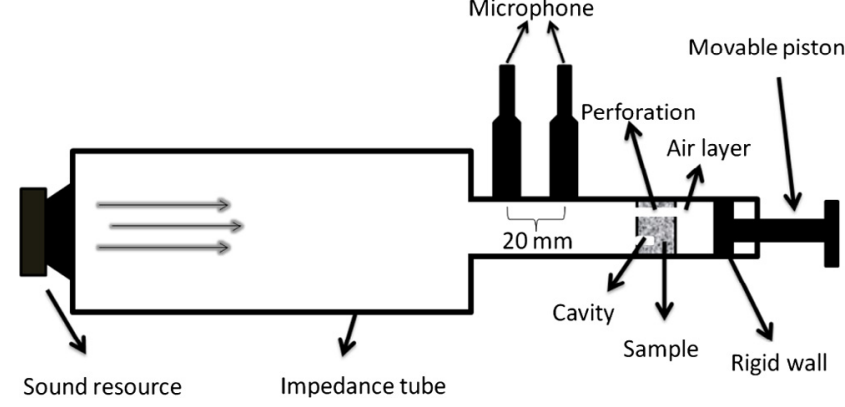

Fig. 2. Schematic diagram of the sound absorption system for high-frequency testing.

\subsection{Methods}

\subsubsection{Samples preparation}

The waste plastic film was first mixed with azodicarbonamide at $160{ }^{\circ} \mathrm{C}$ and then subjected to foaming at $195^{\circ} \mathrm{C}$ for $30 \mathrm{~min}$. The film was then cooled down to room temperature for demolding. The porous structure of the material was formed by the foaming procedure. The crust layer on the surface was removed to expose the pore structure and produce samples with a diameter of 10 and $2.9 \mathrm{~cm}$ for the low- and high-frequency experiments. The synthesized products had a thickness of $1 \mathrm{~cm}$. These treatments resulted in the formation of perforations and cavities (diameter $0.3 \mathrm{~cm}$ ) drilled in the samples by the electric drill. The cavities on the side (of the samples) under observation were $0.5 \mathrm{~cm}$ deep as shown in Figs. 3 and 4 . The air layer thickness was adjusted by the moveable piston as shown in Figs. 1 and 2.

\subsubsection{Sound absorption coefficient tests}

Sound absorption coefficients were measured in accordance with ISO 10534-2. Low-frequency experiments were designed using response surface method, with three parameters and three levels for each parameter, i.e. foaming agent content $(1,1.5$, and $2 \%)$, air layer thickness $(0,1$, and $2 \mathrm{~cm})$, and number of perforations (20,40, and 60), respectively. High-frequency experiments were similarly conducted and the parameters for which were air layer thickness $(0,0.5$, and $1 \mathrm{~cm})$, number of cavities $(0,4$, and 12$)$, foaming agent content $(1.5 \%)$, and number of perforations (4), respectively. The sampling frequency was $2.9 \mathrm{~Hz}$. The area of the lowfrequency samples and high-frequency samples is $7850 \mathrm{~mm}^{2}$ and $7.065 \mathrm{~mm}^{2}$. The relationship between the perforation rate and the number of perforations and cavities is as shown in Table 1.

\subsubsection{Measurement of physical and mechanical properties}

The compression properties were measured in according with ISO 844:2014. Compressive strengths were the pressures at $10 \%$ deformation of the samples.

The densities were calculated from the weights and volumes of the samples according to the follow equation:

$\rho=\mathrm{m} / \mathrm{v}$

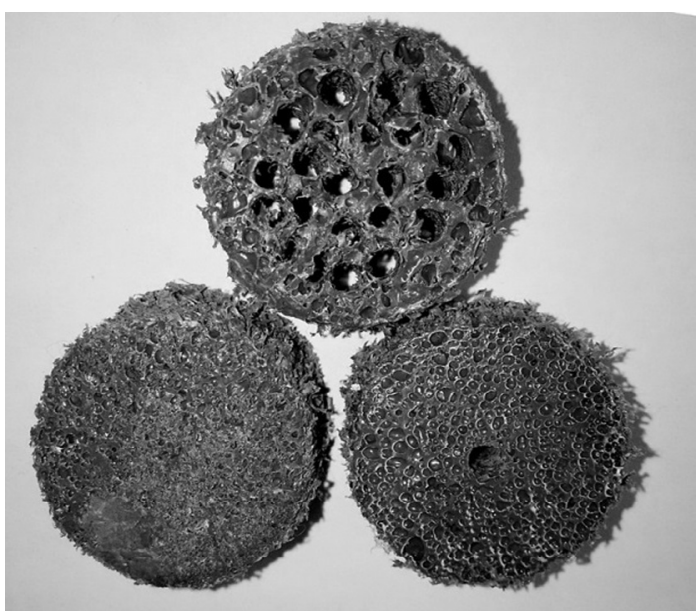

Fig. 3. Picture of the porous samples. 


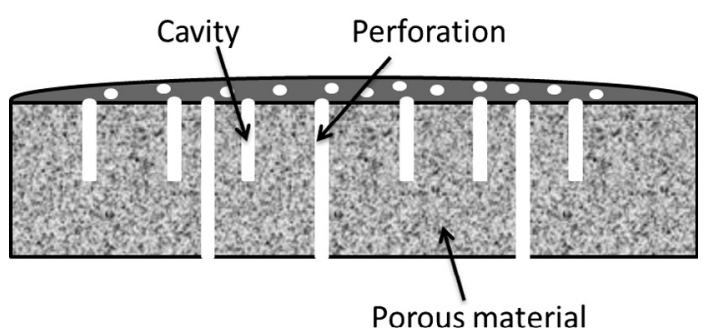

Fig. 4. Vertical section of the porous material with cavities and perforations.

(where $\rho$ is the density, $m$ is the weight of the sample, and $v$ is the volume of the sample.)

The bending properties were measured in according with ISO 1209-1:2004. Flexural strengths were the loads at $20 \mathrm{~mm}$ deformation of the samples.

\subsubsection{Interfering tests}

In order to evaluate the sound absorption properties under raining and sandstorm situations, water and sand were introduced into the perforations and cavities of the materials. Sound absorption coefficients were determined when the perforations and cavities were fully filled with water or sand.

\section{Results and discussion}

\subsection{Low-frequency results}

As shown in Fig. 5, the optimum sound absorption coefficient was 0.44 as the air layer thickness was $1 \mathrm{~cm}$, the average sound absorption coefficients of the synthesized materials increased from 0.16 to a peak value of 0.44 and then decreased as the air layer thickness varied from 0 to $2 \mathrm{~cm}$. The absorption peak moved toward the low-frequency region and its intensity decreased gradually as the thickness of the air layer increased. Therefore, determining the optimum air layer thickness was necessary for generating low-frequency sound absorption of this material.

Fig. 6 illustrates that the average sound absorption coefficients of the materials increased to 0.44 and then decreased to 0.31 as the foaming agent content increased from $1 \%$ to $2 \%$. At a foaming agent content of $1.5 \%$, the material consisted of a large number of evenly distributed cells. Some of these cells connected with each other and formed an open-pore structure. At low foaming agent contents, the material consisted of a lesser number of cells. Hence, a uniform porous structure could not be formed. On the contrary, when the foaming agent content was higher than a certain value, the cells collapsed and merged into larger cells, thus it would limit the sound absorption ability of the material.

Fig. 7 illustrates that the absorption peak of the material moved toward the high-frequency region with an increase in the number of perforations. The average sound absorption coefficient increased from 0.35 to 0.44 and then decreased with an increase in the number of perforations. This can be attributed to the Helmholtz resonance effect of the perforated plates with back air layer. When the number of perforations was small, a narrow absorption peak was observed in the low-frequency region. The frequency and width of the absorption peak increased with an increase in the number of perforations. However, a continued increase in the number of perforations weakened the resonance effect and decreased the sound absorption coefficient.

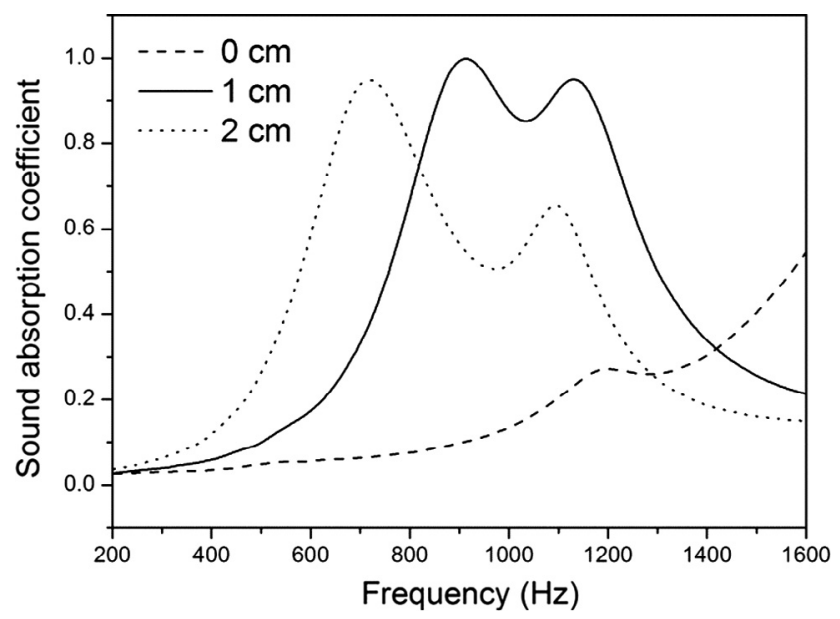

Fig. 5. Sound absorption coefficients obtained under different air layer thicknesses Conditions: $1.5 \%$ foaming agent content and 40 perforations in the frequency range of $200-1600 \mathrm{~Hz}$

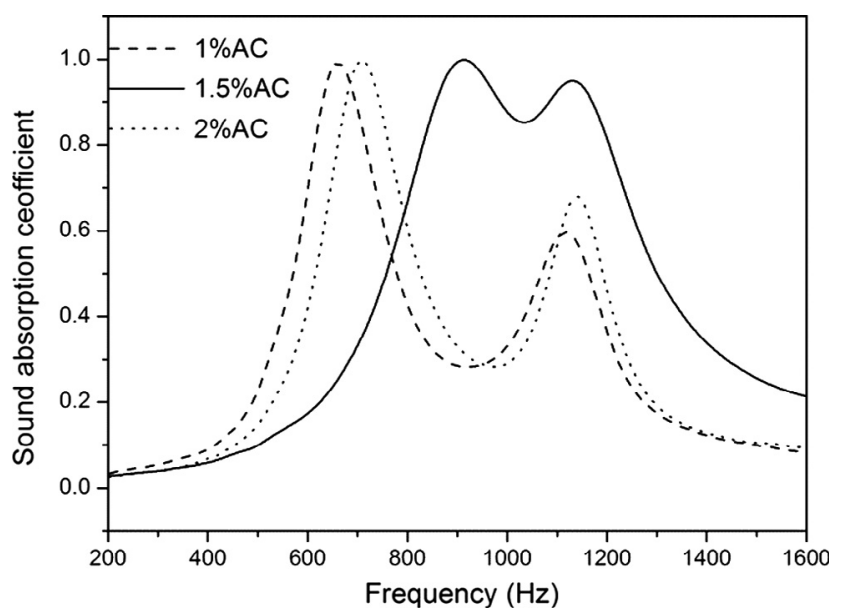

Fig. 6. Sound absorption coefficients obtained under different foaming agent content. Conditions: $1 \mathrm{~cm}$ air layer thicknesses and 40 perforations in the frequency range of $200-1600 \mathrm{~Hz}$

\subsection{High-frequency results}

The high-frequency samples prepared with the optimal foaming agent content (1.5\%) and perforation rate (4\%) derived from lowfrequency experiments.

As shown in Fig. 8, a prominent sound absorption in the lowfrequency region was obtained when a $1 \mathrm{~cm}$ thick air layer was added to the perforated porous plate. However, the sound absorption ability declined significantly in the range $1301-6400 \mathrm{~Hz}$. Moreover, the average sound absorption coefficient declined from 0.47 to 0.37 . This phenomenon is more obvious for the traditional perforation plate.

Porous materials can be used as perforated plates to achieve better sound absorption effect. When the perforated plate has no air layer, the sound absorption at high-frequency is remarkable. However, when the air layer is added, the low-frequency absorp-

Table 1

The correspondence between the perforation rate and the number of perforations/cavities.

\begin{tabular}{|c|c|c|c|c|c|c|}
\hline The number of perforations/cavities & 4 & 8 & 12 & 20 & 40 & 60 \\
\hline Perforation rate (high-frequency sample) & $4 \%$ & $8 \%$ & $12 \%$ & $\backslash$ & $\backslash$ & $\backslash$ \\
\hline Perforation rate (low-frequency sample) & $\backslash$ & $\backslash$ & $\backslash$ & $1.8 \%$ & $3.6 \%$ & $5.4 \%$ \\
\hline
\end{tabular}




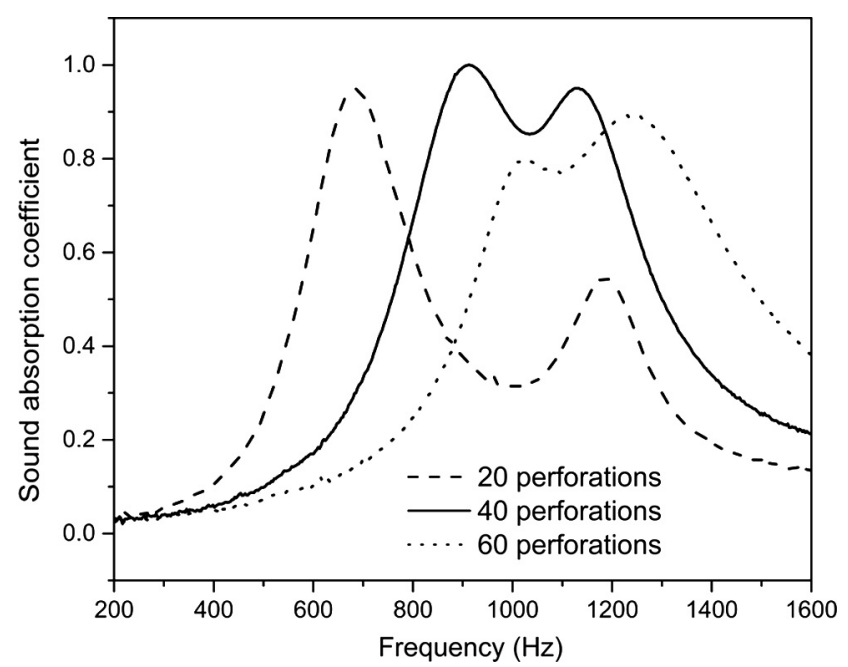

Fig. 7. Sound absorption coefficients obtained under different numbers of perforations. Conditions: $1.5 \%$ foaming agent content and $1 \mathrm{~cm}$ air layer thicknesses in the frequency range of $200-1600 \mathrm{~Hz}$.

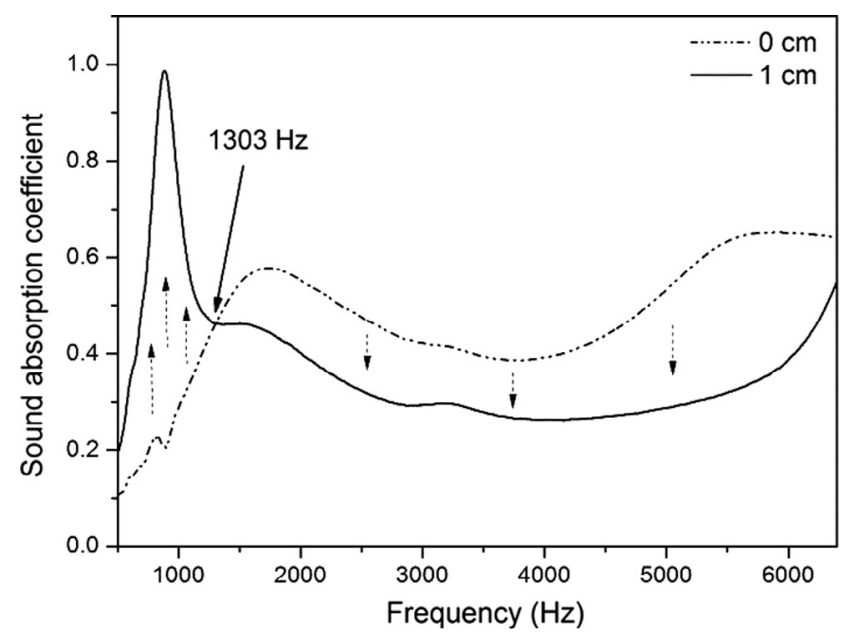

Fig. 8. Sound absorption coefficients obtained at different air layer thicknesses in the frequency range of 500-6400 Hz. Condition: four perforations.

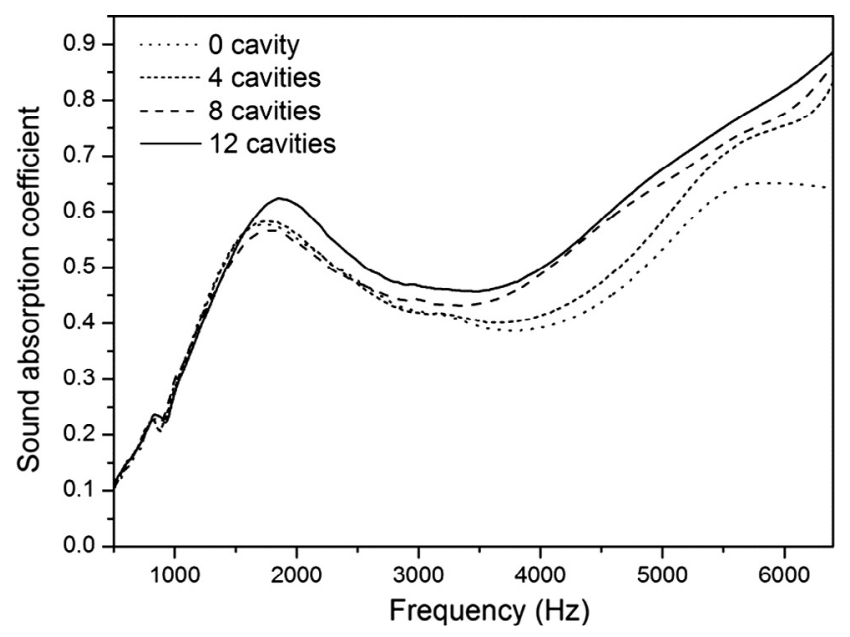

Fig. 9. Sound absorption coefficients obtained at different number of cavities in the frequency range of $500-6400 \mathrm{~Hz}$. tion is obvious, but the high-frequency sound absorption performance decreases.

As shown in Fig. 9, when the number of cavities was increased from 0 to 12, the sound absorption coefficient increased from 0.47 to 0.55 within the frequency range $500-6400 \mathrm{~Hz}$. Meanwhile, in the low-frequency range, the effect of the cavities on the absorption ability of the material was diminished. Therefore, cavities could increase the sound absorption ability of porous materials at high frequencies when there was no air layer. The relationship between the number of cavities and the average sound coefficient was found to be linear (Fig. 10) in accordance with the equation $\mathrm{y}=0.0068 \mathrm{x}+0.472$ ( $\mathrm{y}$ is the average sound coefficient; $\mathrm{x}$ is the number of cavities, $0 \leq \mathrm{x} \leq 12$ ).

As shown in Fig. 11, the cavities enhanced the sound absorption ability of the perforated porous plate in the high-frequency range but had no notable effect in the low-frequency range when there was an air layer. The relationship between the number of cavities and the average sound coefficient was linear (Fig. 12) as per the equation $\mathrm{y}=0.0133 \mathrm{x}+0.373$ ( $\mathrm{y}$ is the average sound coefficient; $\mathrm{x}$ is the number of cavities, $0 \leq \mathrm{x} \leq 12$ ).

As shown in Fig. 13, increasing the thickness of air layer made the maximum sound absorption peak move to low frequencies, but had only a minor effect on the high-frequency absorption ability. The low frequency absorption peak could be adjusted by the thickness of the air layer. Meanwhile, the high frequency sound absorption was remarkable. Therefore, we obtained a comprehensive sound absorption material that shows excellent performance in both low- and high-frequency ranges. The relationship between the frequency of the maximum absorption peak and the thickness of air layer could be represented as a power function (Fig. 14), that is $\mathrm{y}=885.05 \mathrm{x}^{-0.447}$ ( $\mathrm{y}$ is the frequency of maximum absorption peak; $x$ is the thickness of air layer, $0.5 \leq x \leq 3$ ).

According to the above results, this new material has a wide range of applications, including indoor and outdoor. The noise in classrooms, theaters and ticket offices mainly comes from human beings (the frequency range is $200-2000 \mathrm{~Hz}$ ). Thus, two or three different air layer thicknesses should be used together. The subway and high-speed railway have both high-frequency noise (such as aerodynamic noise and pantograph's noise) and low frequency noise, which come from the wheels and the rails. The main frequency is $500 \mathrm{~Hz}$. Therefore, it is suitable to use perforated plates with the air layers of $3 \mathrm{~cm}$ thickness, and the cavities made of the porous materials. The noise could be absorbed by the porous materials with different acoustic structures. The diagram is shown in Fig. 15.

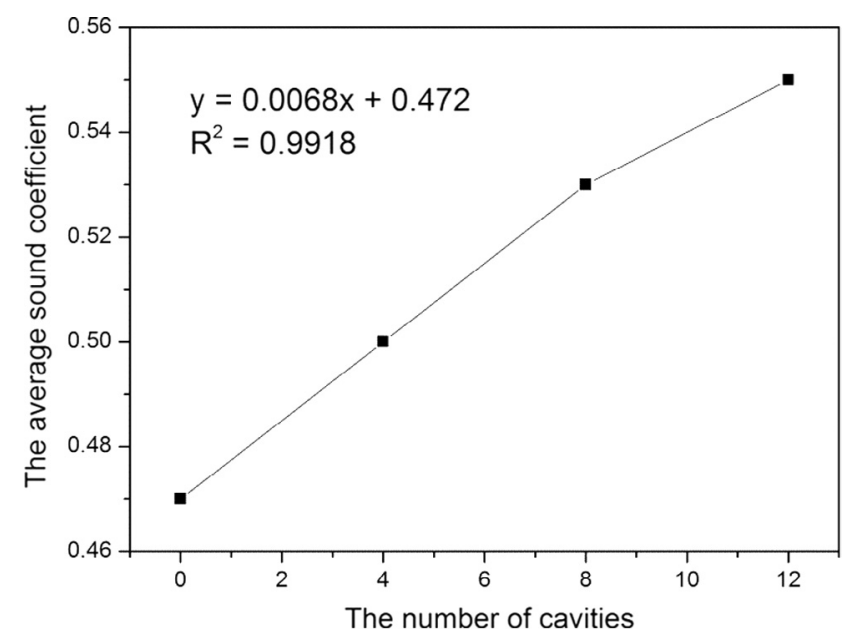

Fig. 10. Relationship between the number of cavities and the average sound absorption coefficients. 


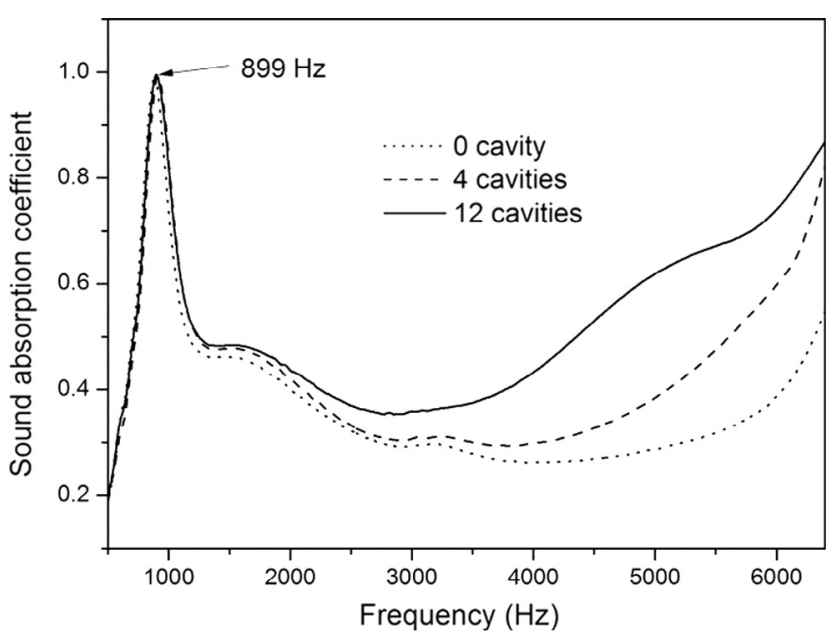

Fig. 11. Sound absorption coefficients obtained at different numbers of cavities in the frequency range of $500-6400 \mathrm{~Hz}$. Conditions: four perforations and $1 \mathrm{~cm}$ air layer thickness.

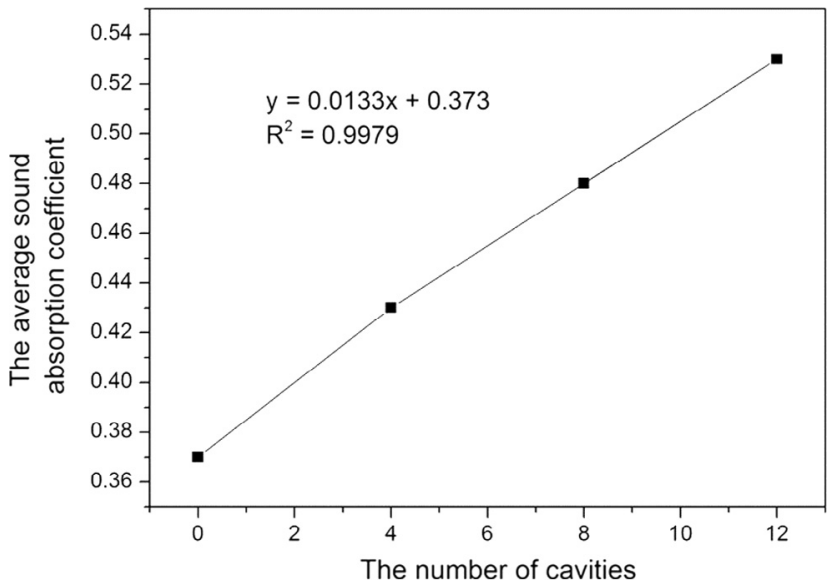

Fig. 12. Relationship between the number of cavities and average sound absorption coefficients. Conditions: four perforations and $1 \mathrm{~cm}$ air layer thickness.

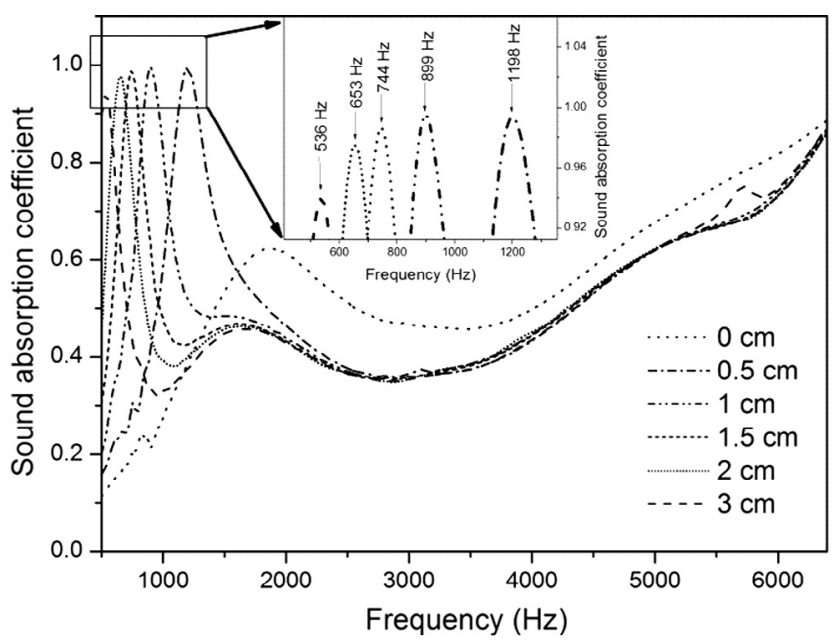

Fig. 13. Sound absorption coefficients obtained at different air layer thicknesses in the frequency range of $500-6400 \mathrm{~Hz}$. Conditions: four perforations and twelve cavities.

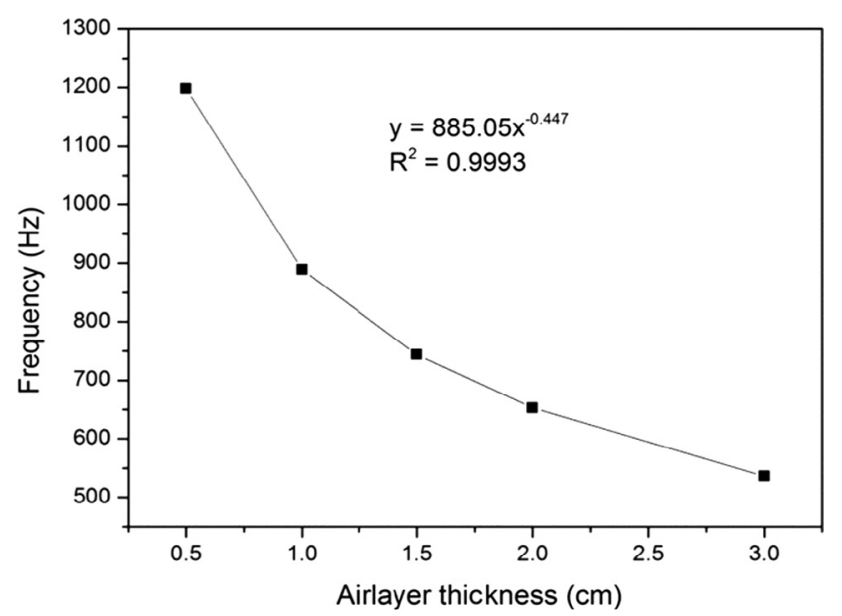

Fig. 14. Relationship between air layer thickness and frequency of the maximum absorption peak. Conditions: four perforations and twelve cavities.

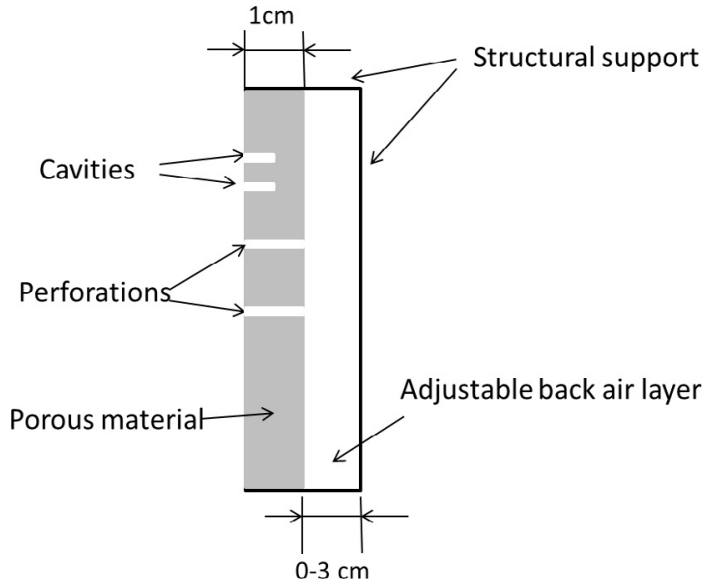

Fig. 15. Diagram of the sound absorption material.

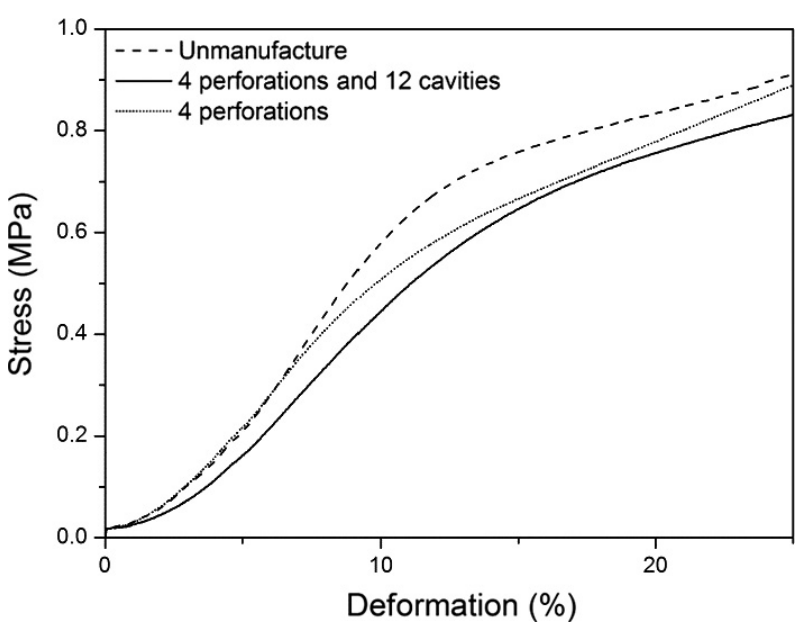

Fig. 16. Compressive strength of the samples with different manufactures. Condition: $1.5 \%$ foaming agent content.

\subsection{Mechanical properties}

As is shown in Fig. 16, the compressive strength of the samples which have containing $1.5 \%$ foaming agent was investigated under 
different manufactures (perforations and cavities). The compressive strength decreased as the number of perforations and cavities increased. The compressive strength of the samples were $0.56 \pm 0.01 \mathrm{MPa}$ (unmanufactured), $0.51 \pm 0.01 \mathrm{MPa}$ (4 perforations) and $0.45 \pm 0.02 \mathrm{MPa}$ ( 4 perforations and 12 cavities), respectively. The compressive strength was greater than the Chinese standard of polymer foam board for application in highway engineering (JT/T 538-2004) and building (QB/T 3806-1999).

The average density of the samples was $0.55 \mathrm{~g} / \mathrm{cm}^{3}$ when five samples were tested. It is lighter than the sound absorption materials made from fly ash [16] and coal bottom ash [17]. Calculated by the weight, $600 \mathrm{~m}^{2}$ waste agriculture film could be recycled and made into $1 \mathrm{~cm}^{2}$ this sound absorption material (regarding the thickness of waste agriculture film as $0.01 \mathrm{~mm}$ ).

The average flexural strength of the sample was $91.20 \pm 1.22 \mathrm{~N}$ when the deformation was $20 \mathrm{~mm}$, and it's greater than that of similar decorating and acoustic ceiling material (GB/T 259982010).

\subsection{Interfering results}

As shown in Fig. 17, the sound absorption coefficient dropped sharply in all frequency ranges when water was filled in the perforations and cavities. Low frequency absorption was decreased and high frequency absorption was increased when sand was filled into the perforations and cavities. It indicated that water or sand obstructed the air connection between air layer and the outside. Thus, low frequency sound absorption dropped as the resonant effect vanished. Meanwhile, water kept the sound wave from entering into the cavities and the high frequency sound absorption declined drastically. However, sound absorption coefficients increased in high frequency range since there were numerous fine interspaces and reflectors formed inside sand particles in the perforations and cavities. The interspaces and reflectors generated sound absorption [18] similar to porous materials in high frequency range.

\section{Conclusions}

A novel porous sound absorption material with perforations, cavities, and an air layer was successfully developed from waste agriculture film. Two frequency ranges were investigated, and the material exhibited high sound absorption efficiency at both

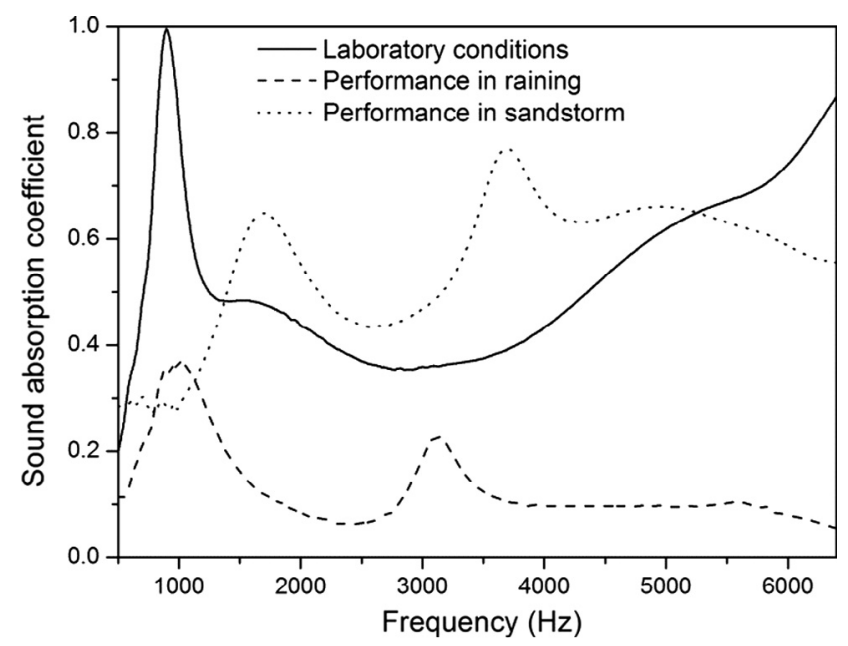

Fig. 17. Sound absorption coefficients when water or sand was filled in the perforations and cavities. Conditions: four perforations, twelve cavities and a $1 \mathrm{~cm}$ air layer. low and high frequency ranges. The perforations and air layers can absorb low-frequency noise, and porous materials with cavities can absorb high-frequency noise. The low-frequency absorption peak could be controlled by controlling the number of perforations and the thickness of the air layer. The highfrequency absorption could be enhanced by cavities. The price of waste agriculture film is half of the polyethylene raw material. The density of the material is $0.55 \mathrm{~g} / \mathrm{cm}^{3}$. Thus, this material is lighter and cheaper than traditional sound absorption materials, and thus has potential for a wider range of applications. The compressive strengths declined with perforations and cavities added. Water coverage could weaken the sound absorption efficiency in all frequency ranges, while sand coverage could weaken the low frequency absorption, but could increase the high frequency absorption efficiency. Moreover, as this material could be made from inexpensive waste agricultural plastic film, the proposed approach not only yields a high value-added environmental material but also improves the pollution control of waste plastics.

\section{Acknowledgements}

This research was made possible by financial support from the National Nature Science Foundation of China (21477151), the National Water Pollution Control and Management Program (2012ZX07202-005), the Strategic Priority Research Program of the Chinese Academy of Sciences (XDB05050200) and the Science Promotion Program of Research Center for Eco-Environmental Sciences, CAS (YSW2013B05).

\section{References}

[1] Z. Steinmetz, C. Wollmann, M. Schaefer, C. Buchmann, J. David, J. Troger, K. Munoz, O. Fror, G.E. Schaumann, Plastic mulching in agriculture. Trading shortterm agronomic benefits for long-term soil degradation?, Sci Total Environ. 550 (2016) 690-705, http://dx.doi.org/10.1016/j.scitotenv.2016.01.153.

[2] X.D. Li, Z.Y. Song, T. Wang, Y. Zheng, X. Ning, Health impacts of construction noise on workers: a quantitative assessment model based on exposure measurement, J. Cleaner Prod. 135 (2016) 721-731, http://dx.doi.org/ 10.1016/j.jclepro.2016.06.100.

[3] S. Pirrera, E. De Valck, R. Cluydts, Nocturnal road traffic noise: a review on its assessment and consequences on sleep and health, Environ. Int. 36 (5) (2010) 492-498, http://dx.doi.org/10.1016/j.envint.2010.03.007.

[4] J. Xiao, X.D. Li, Z.H. Zhang, DALY-based health risk assessment of construction noise in Beijing, China, Int. J. Env. Res. Public Health 13 (11) (2016) 1045, http://dx.doi.org/10.3390/ijerph13111045.

[5] C.R. Kight, J.P. Swaddle, How and why environmental noise impacts animals: an integrative, mechanistic review, Ecol. Lett. 14 (10) (2011) 1052-1061, http://dx.doi.org/10.1111/j.1461-0248.2011.01664.x.

[6] A.E. Tiuc, H. Vermesan, T. Gabor, O. Vasile, Improved sound absorption properties of polyurethane foam mixed with textile waste, Energy Procedia 85 (2016) 559-565, http://dx.doi.org/10.1016/j.egypro.2015.12.245.

[7] A. Byakova, Y. Bezim'yanny, S. Gnyloskurenko, T. Nakamura, Fabrication method for closed-cell aluminium foam with improved sound absorption ability, Procedia Mater. Sci. 4 (2014) 9-14, http://dx.doi.org/10.1016/j. mspro.2014.07.573.

[8] G. Wu, R. Li, Y. Yuan, L. Jiang, D. Sun, Sound absorption properties of ceramic hollow sphere structures with micro-sized open cell, Mater. Lett. 134 (2014) 268-271, http://dx.doi.org/10.1016/j.matlet.2014.07.082.

[9] O. Kinnane, A. Reilly, J. Grimes, S. Pavia, R. Walker, Acoustic absorption of hemp-lime construction, Constr. Build. Mater. 122 (2016) 674-682, http://dx. doi.org/10.1016/j.conbuildmat.2016.06.106.

[10] L. Fan, Z. Chen, S.Y. Zhang, J. Ding, X.J. Li, H. Zhang, An acoustic metamaterial composed of multi-layer membrane-coated perforated plates for lowfrequency sound insulation, Appl. Phys. Lett. 106 (15) (2015) 151908, http:// dx.doi.org/10.1063/1.4918374.

[11] V. Phong, D. Papamoschou, Normal incidence acoustic insertion loss of perforated plates with bias flow, J. Acoust. Soc. Am. 138 (6) (2015) 39073921, http://dx.doi.org/10.1121/1.4937602.

[12] X.D. Zhao, X.Q. Fan, Enhancing low frequency sound absorption of microperforated panel absorbers by using mechanical impedance plates, Appl. Acoust. 88 (2015) 123-128, http://dx.doi.org/10.1016/j.apacoust.2014.08.015.

[13] Y.J. Qian, D.Y. Kong, S.M. Liu, S.M. Sun, Z. Zhao, Investigation on microperforated panel absorber with ultra-micro perforations, Appl. Acoust. 74 (7) (2013) 931-935, http://dx.doi.org/10.1016/j.apacoust.2013.01.009. 
[14] I. Vican, K. Jambrosic, H. Domitrovic, Improvement of acoustic resistance equations in perforated plate absorbers with thin porous layers, Noise Control Eng. J. 63 (5) (2015) 415-423, http://dx.doi.org/10.3397/1/376337.

[15] M. Toyoda, K. Sakagami, M. Okano, T. Okuzono, E. Toyoda, Improved sound absorption performance of three-dimensional MPP space sound absorbers by filling with porous materials, Appl. Acoust. 116 (2017) 311-316, http://dx.doi. $\operatorname{org} / 10.1016 /$ j.apacoust.2016.10.006.

[16] C. Leiva, C. Arenas, L.F. Vilches, B. Alonso-Farinas, M. Rodriguez-Galan, Development of fly ash boards with thermal, acoustic and fire insulation properties, Waste Manage. 46 (2015) 298-303, http://dx.doi.org/10.1016/j. wasman.2015.08.027.

[17] C. Arenas, C. Leiva, L.F. Vilches, H. Cifuentes, Use of co-combustion bottom ash to design an acoustic absorbing material for highway noise barriers, Waste Manage. 33 (11) (2013) 2316-2321, http://dx.doi.org/10.1016/j. wasman.2013.07.008

[18] V.V. Voronina, K.V. Horoshenkov, Acoustic properties of unconsolidated granular mixes, Appl. Acoust. 65 (7) (2004) 673-691, http://dx.doi.org/ 10.1016/j.apacoust.2003.12.002. 